\title{
Comparison of antimicrobial study of extracted essential oil clove and readymade essential oil neem
}

\section{Patel Prachi $\mathbf{S}^{*}$ and Desai Reena G.}

Dolat-Usha Institute of Applied Sciences and Dhiru- Sarla Institute of Management and commerce, Valsad, Gujarat, India, Pin code-396001

\begin{abstract}
A bstract: Essential oils are widely used in the treatment of skin disease. They are also important as a flavouring agent in the food industry. Clove essential oil is used traditionally as flavouring agent and antimicrobial material in food. Neem oil is beneficial to the skin. The study was done on antibacterial and antifungal activities of extracted and readymade essential oils of clove spice and Neem herb. The further study of total phenolic content of essential oils. The essential oils of spice and herb showed antibacterial and antifungal activities which were tested against Gram negative bacteria such as Escherichia coli(ATCC 9961), Proteus vulgaris(ATCC 25933), Salmonella typhi(ATCC 23564), Pseudomonas aeruginosa(ATCC 19154), Gram positive bacteria Staphylococcus aureus(ATCC 6538) and filamentous fungi Aspergillus niger(ATCC 934), Mucor sp.(ATCC 1279), Penicillium sp.(ATCC 28682). Agar well diffusion assay was performed to study the antibacterial and antifungal activities of essential oils. Total phenolic content of essential oils was measured by Folin-Ciocalteu method. Highest antibacterial activity of clove oil observed at $100 \mu \mathrm{l}$ concentration, gave $19 \mathrm{~mm}$ zone of inhibition against Pseudomonas aeruginosa. Highest antifungal activity of clove oil observed at $100 \mu \mathrm{l}$ concentration, gave $31 \mathrm{~mm}$ against Aspergillus niger and Penicillium sp. And also found that clove essential oil have $23.44 \mathrm{mg} / \mathrm{g}$ highest phenolic compound. Phenolic compound is most important compound which is responsible for antibacterial and antifungal activities. The study reported important and comparison of spice and herb essential oils and their used as antibacterial and antifungal agent in pharmaceutical and food industry.
\end{abstract}

K eywords: Essential oil, Clove, Neem, Antimicrobial activity, Total phenolic content.

*Author for Correspondence. E-mail: pprachi431@gmail.com

www. ijamicro.com 


\section{Introduction}

Microbial contamination is the important factor for developing food-borne diseases and food spoilage. Multidrug resistance of these microorganisms is a major medical problem. It is important to search for new natural alternative having antimicrobial activity such as plant extracts and essential oils [1]. Over the past two or three decades many beneficial effects of the common food spices and herbs on the health have been understood [2]. Essential oils obtained from plants are used against many skin diseases. Essential oils are mixture of volatile compounds. These volatile compound acts as protective substances against microorganisms. Phenolic compounds and terpens are the main biological constituents in the essential oil $[3,4,5]$. Essential oils are used as carminative, stomachic, stimulant, and aromatic, antiseptic [6] and as a flavouring agent in beverages, foods, cosmetics, and household products [7]. Clove essential oil is obtained from Syzygium aromaticum. Neem essential oil is obtained from Azadirachta indica. In this study, we investigated the in-vitro antimicrobial effects of two essential oils of spice and herb against 5 bacteria Escherichia coli(ATCC 9961), Staphylococcus aureus(ATCC 6538), Proteus vulgaris(ATCC 25933), Salmonella typhi(ATCC 23564), Pseudomonas aeruginosa(ATCC 19154) and 3 fungal Aspergillus niger(ATCC 934), Mucor sp.(ATCC 1279), Penicillium sp.(ATCC 28682) respectively and further analysed the total phenolic content of 2 essential oils.

\section{M aterials and $M$ ethods}

\subsection{Collection and Preparation of spice mixture}

Clove spice and readymade essential oil of Neem herb were purchased from local store (in Valsad, Gujarat, India).The spice was milled to fine powder for extraction of essential oil. $100 \mathrm{~g}$ of the spice powder was taken, mixed with $500 \mathrm{ml}$ of sterile distilled water and allow it soaked for overnight.

\subsection{Microorganisms}

Standard strains of Escherichia coli(ATCC 9961), Staphylococcus aureus(ATCC 6538), Proteus vulgaris(ATCC 25933), Salmonella typhi(ATCC 23564), and Pseudomonas aeruginosa(ATCC 19154)microorganisms were used for detection of the antibacterial activity. Aspergillus niger(ATCC 934), Mucor sp.(ATCC 1279), Penicillium sp.(ATCC 28682)were used for detection antifungal activity. Bacteria and fungi were stored on Nutrient agar medium and Sabouraud dextrose agar medium till the analysis.

\subsection{Extraction of essential oil}

The essential oil of spice was extracted by steam distillation method (modified), using $100 \mathrm{~g}$ of spice powder was mixed with $500 \mathrm{ml}$ sterile distilled water and subject to steam distillation process for 3-4 hours. After completion of process two separate layer of oil and water was observed and separation of oil was carried out with use of separating funnel. Extracted oil was kept in the desiccator for the dehydration of remaining water for 24 to 48 hours and stored it at $4^{\circ} \mathrm{C}$ until used [9]. 


\subsection{Evaluation of antimicrobial activity using agar well diffusion technique}

Antibacterial and Antifungal activity was determined by agar well diffusion method [8]. Antibacterial activity of extracted essential oil was studied using Muller-Hinton agar medium (HiMedia, India), and the antifungal activity of the essential oils were studied using Sabouraud dextrose agar medium. Using pour plate method, one tube of melted Muller-Hinton agar was taken and $0.1 \mathrm{ml}$ of bacterial inoculum $\left(6 \times 10^{5} \mathrm{CFU} / \mathrm{ml}\right)$ was inoculated in melted agar tube. It was then mixed and poured into empty sterile petri dish, allowed to solidify. After it was solidified, $6 \mathrm{~mm}$ diameter well was bored on the surface of all selected sterile agar plates. Antimicrobial activity using diffusion assay, different concentrations like 50, 75, 100, 150, 200, 300 and $400 \mu \mathrm{l}$ of essential oil was taken and reconstituted with $0.25 \mathrm{ml}$ of dimethylsulfoxide (DMSO) and $0.1 \mathrm{ml}$ tween 80 mixtures. From the mixture, $20 \mu \mathrm{l}$ was pipetted into wells. Plates were allowed to stand for $30 \mathrm{~min}$ for prediffusion of reconstituted essential oil. Plates were incubated at $37^{\circ} \mathrm{C}$ and room temperature for $24 \mathrm{~h}$. Plates were examined and zone of inhibition was measured in millimetre (mm). DMSO used as negative control to check that DMSO itself does not give any zone of inhibition.

\subsection{Estimation of total phenolic content}

The total phenolic content present in essential oils were estimated by Folin-Ciocalteu method with slight modification [9]. Gallic acid was used as a reference standard for plotting calibration curve [10]. A different volume in millilitre of essential oils of spices and herbs were taken in the separate sterile tubes and adjust volume to $1 \mathrm{ml}$ by adding ethanol. Then tubes were incubated at $70^{\circ} \mathrm{C}$ in water bath for 20 mins. After the incubation $1 \mathrm{ml}$ Folin-Ciocalteu reagent (diluted 1:10 with DMSO (modified) was added in all tubes. After $3 \mathrm{~min}, 1 \mathrm{ml}$ of $\mathrm{Na}_{2} \mathrm{CO}_{3}$ solution (2\%) was added and mixture was allowed to stand for $2 \mathrm{~h}$ with intermittent shaking for colour development. The absorbance of the resulting blue colour was measured at $760 \mathrm{~nm}$ [11]. The total phenolic content was determined from liner equation of standard. The content of total phenolic compound was expressed as mg Gallic acid equivalent/g (mg GAE/g) of dry mass.

\section{R esults and Discussion}

\subsection{Extraction of essential oil}

Essential oils are complex mixture of wide variety of compound and have been recognized for their antibacterial, antifungal and antioxidant properties. Essential oil was extracted from the previously prepared fine powder and overnight soaked clove by the steam distillation process in the laboratory. Table 1 indicated extraction of essential oil.

Table 1.E ssential oil extracted by steam distillation from clove spice

\begin{tabular}{|l|c|}
\hline Sample & Yields of essential oils (\%) \\
\hline Clove & 2.6 \\
\hline
\end{tabular}


According to table 1 we were obtained $2.6 \%$ yield of essential oil from $100 \mathrm{~g}$ of each Clove.

\subsection{Evaluation of antimicrobial activity}

Antibacterial and Antifungal activity was determined by agar well diffusion method. Table 2 and 3 clearly shows that Clove spice and Neem herb essential oils were effective against the bacteria and fungi that were used in study.

Table 2.Antibacterial activity of essential oils at $50,75,100,150 \mu l$ by agar well diffusion assay

\begin{tabular}{|l|c|c|c|c|c|c|c|c|}
\hline \multicolumn{7}{|c|}{ Zone of inhibition (mm) } \\
\hline Sample Concentration & $50 \mu 1$ & $75 \mu 1$ & $100 \mu 1$ & $150 \mu 1$ & $50 \mu 1$ & $75 \mu 1$ & $100 \mu 1$ & $150 \mu 1$ \\
\hline Organisms & & & & & & & & \multicolumn{2}{l|}{ Neem } \\
\hline Escherichia coli & 12 & 12 & 12 & 13 & 12 & 12 & 13 & - \\
\hline Salmonella typhi & - & 12 & 11 & 13 & - & - & - & - \\
\hline Staphylococcus aureus & - & 11 & 11 & 12 & - & - & - & - \\
\hline Proteus vulgaris & 12 & 13 & 11 & 13 & 13 & - & 14 & - \\
\hline Pseudomonas aeruginosa & - & 12 & 19 & - & - & - & - & - \\
\hline
\end{tabular}

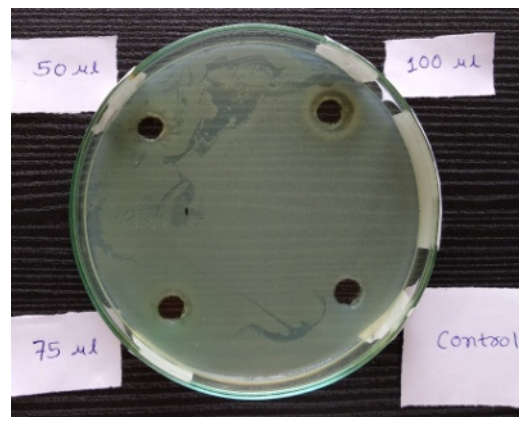

It was found that in Clove spice essential oil showed the highest antibacterial and antifungal activities than Neem herb essential oil. In antibacterial activity, clove essential oil shows $19 \mathrm{~mm}$ highest zone of inhibition against Pseudomonas aeruginosa at $100 \mu \mathrm{l}$ concentration of oil. While clove oil with other studied bacteria were also gave highest antibacterial activity at the increase concentration to $150 \mu 1$. Other three gram negative bacteria Escherichia coli, Salmonella typhi and Proteus vulgaris were inhibited by clove essential oil and shows decreased inhibition zone size to $13 \mathrm{~mm}$. Gram positive bacteria Staphylococcus aureus showed less inhibition zone size of $12 \mathrm{~mm}$. Neem essential oil was more effective against Proteus vulgaris and gave $14 \mathrm{~mm}$ zone of 
inhibition at $100 \mu \mathrm{l}$ concentration of oil. Escherichia coli was also inhibited at $100 \mu$ l concentration and give $12 \mathrm{~mm}$ zone of inhibition. While remaining other bacteria Salmonella typhi, Staphylococcus aureus and Pseudomonas aeruginosa were showed resistance towards Neem oil. The antibacterial activity of spice essential oil obtained by agar well diffusion assay in our study were higher than to the results obtained by El Kady et al; (1993). The antibacterial activity of herb essential oil obtained by agar well diffusion assay were less than to the results obtained by K. Upadhyay et al; (2010).

Table 3.Antifugal activity of essential oils at $50,75,100 \mu l$ by agar well diffusion assay

\begin{tabular}{|l|l|l|l|l|c|c|}
\hline \multicolumn{6}{|c|}{ Zone of inhibition (mm) } \\
\hline \multicolumn{1}{|c|}{ Sample } & \multicolumn{5}{c|}{ Clove } & \multicolumn{3}{c|}{ Neem } \\
\hline Concentration & $50 \mu 1$ & $75 \mu 1$ & $100 \mu 1$ & $50 \mu 1$ & $75 \mu 1$ & $100 \mu 1$ \\
Organisms & & & & & & \\
\hline Aspergillus niger & 12 & 30 & 31 & - & - & - \\
\hline Mucor sp. & 11 & 27 & 28 & - & - & - \\
\hline Penicillium sp. & 27 & 30 & 31 & - & - & - \\
\hline
\end{tabular}

In antifungal activity, Aspergillus niger and Penicillium sp. were showed highest $(31 \mathrm{~mm})$ zone of inhibition with clove essential oil at $100 \mu \mathrm{l}$ concentration. While clove oil was tested against Mucor sp., gave $28 \mathrm{~mm}$ zone of inhibition at $100 \mu \mathrm{l}$ concentration. All fungi were resistance against Neem essential oils at $50 \mu 1,75 \mu 1$ and $100 \mu 1$ concentration. Therefore same assay was run with higher concentration.

Table 4.A ntifungal activity of Neem essential oil at $200 \mu l, 300 \mu l$ and $400 \mu l$ done by agar well diffusion assay

\begin{tabular}{|l|c|c|c|}
\hline \multicolumn{4}{|c|}{ Zone of inhibition (mm) } \\
\hline \multicolumn{1}{|c|}{ Sample } & \multicolumn{3}{c|}{ Neem } \\
\hline Concentration & $200 \mu 1$ & $300 \mu 1$ & $400 \mu 1$ \\
Organisms & & & \\
\hline Aspergillus niger & - & - & - \\
\hline Mucor sp. & 10 & 10 & 11 \\
\hline Penicillium sp. & - & - & - \\
\hline
\end{tabular}

Table 4 showed Antifungal activity of Neem essential oils at $200 \mu 1,300 \mu \mathrm{l}$ and $400 \mu 1$ concentration. Neem essential oil showed antifungal activity only against Mucor sp. at $400 \mu 1$ concentration. 

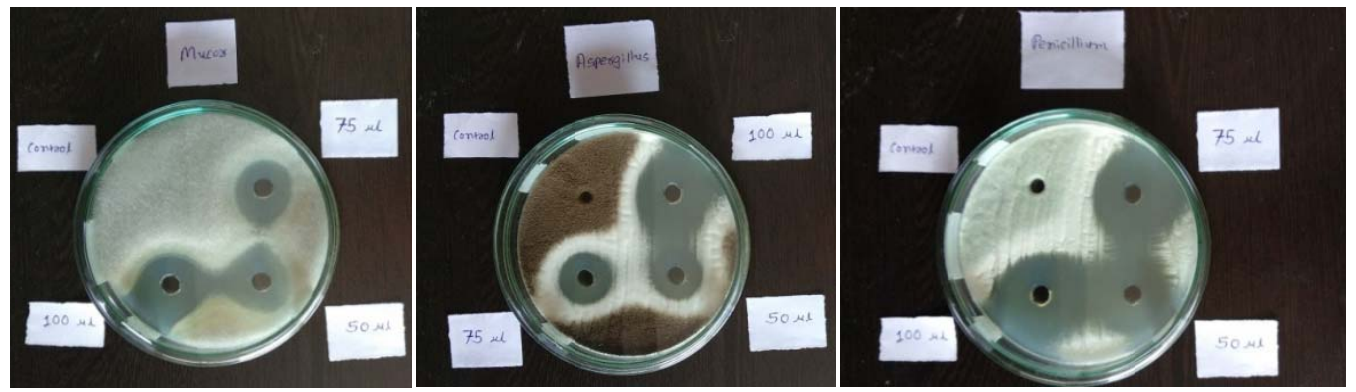

\subsection{Estimation of total phenolic content}

Biological activities related to antibacterial and antifungal activities may be correlated with total phenolic content [8]. The results of the present study showed that clove essential oil had highest activity in compare to Neem herb essential oil.

Figure $1 \mathrm{G}$ allic acid standard curve

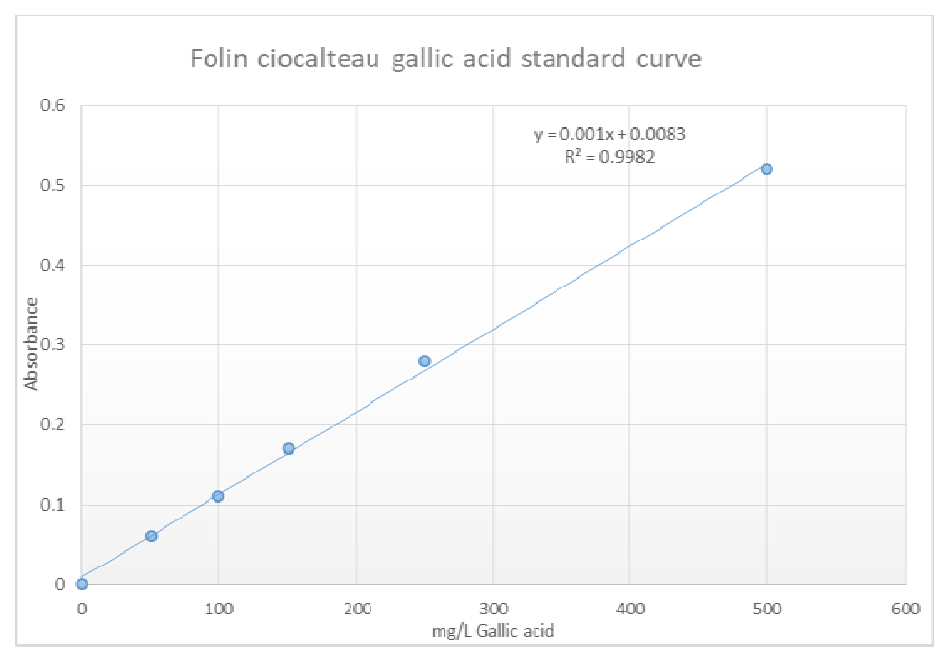

Figure 1 showed standard Gallic acid curve [10]. On the basis of the graph and equation total phenolic content of samples find out.

Table 5. Total phenolic content of samples

\begin{tabular}{|l|c|}
\hline Samples & Total phenolic content(mg/g) \\
\hline Clove & 23.44 \\
\hline Neem & 3.08 \\
\hline
\end{tabular}

In table 5 clearly showed that Clove essential oil has more phenolic content than Neem essential oil. Clove and Neem essential oils have $23.44 \mathrm{mg}$ and $3.08 \mathrm{mg}$ total phenolic content respectively. 


\section{Conclusion}

The results obtained from this study showed that spice and herb essential oils can be considered good source of natural compound for antibacterial and antifungal activities. The present study was showed Clove essential oil have more antibacterial and antifungal activities and total phenolic content than Neem essential oil. Therefore, it can be concluded that Clove essential oil has more effective against few pathogenic and commensal microorganisms and also use as a flavouring agent in beverages, foods, cosmetics, and household products.

\section{R eferences}

1. Shah, P. M. 2005. "The need for new therapeutic agents: what is in the pipeline?". Clinical Microbiology and infection, 11(s3), 36-42.

2. Asimi, O. A., Sahu, N. P., \& Pal, A. K. 2013. "Antioxidant activity and antimicrobial property of some Indian spices”. International Journal Scientific and Research Publications, 541.

3. Noorolahi, Z., Sahari, M. A., Barzegar, M., Doraki, N., \& Naghdi Badi, H. 2013. "Evaluation antioxidant and antimicrobial effects of cinnamon essential oil and echinacea extract in Kolompe”. Journal of Medicinal Plants, 1(45), 14-28.

4. Lin, Y. T., Labbe, R. G., \& Shetty, K. 2005. "Inhibition of Vibrio parahaemolyticus in seafood systems using oregano and cranberry phytochemical synergies and lactic acid". Innovative Food Science \& Emerging Technologies, 6(4), 453-458.

5. Mathew, S., \& Abraham, T. E. 2006. "Studies on the antioxidant activities of cinnamon (Cinnamomum verum) bark extracts, through various in vitro models". Food Chemistry, 94(4), 520-528.

6. Karpińska, M., Borowski, J., \& Danowska-Oziewicz, M. 2001. "The use of natural antioxidants in ready-to-serve food". Food chemistry, 72(1), 5-9.

7. Rao, J., \& McClements, D. J. 2012. "Impact of lemon oil composition on formation and stability of model food and beverage emulsions". Food chemistry, 134(2), 749-757.

8. Okeke, M. I., Iroegbu, C. U., Eze, E. N., Okoli, A. S., \& Esimone, C. O. 2001. "Evaluation of extracts of the root of Landolphia owerrience for antibacterial activity". Journal of ethnopharmacology, 78(2-3), 119-127.

9. Bag, A., \& Chattopadhyay, R. R. 2015. "Evaluation of synergistic antibacterial and antioxidant efficacy of essential oils of spices and herbs in combination". PLOS one, 10(7).

10. Waterhouse, A. 1999. "Folin-Ciocalteu micro method for total phenol in wine". American Journal of Enology and Viticulture, 28, 1-3.

11. McDonald, S., Prenzler, P. D., Antolovich, M., \& Robards, K. 2001. "Phenolic content and antioxidant activity of olive extracts". Food chemistry, 73(1), 73-84.

12. El Kady, IA [الــرزاق القاضـــــ \& El-Maraghy, S. S. 1993. "Antibacterial and antidermatophyte activities of some essential oils from spices". Qatar University Sci. Journal, 13(1), $63-69$.

13. Upadhyay R. K., Dwivedi, P., \& Ahmad, S. 2010. "Screening of antibacterial activity of six plant essential oils against pathogenic bacterial strains". Asian journal. Medical Science, 2(3), 152-158. 